\title{
EDITORIAL
}

\section{Nuclear research and industry today}

\author{
We explore the status of global nuclear research and industry post-Fukushima and find positive \\ developments.
}

On 11 March 2011, the tsunami following a magnitude-9 Tohoku earthquake caused a major nuclear accident at the Fukushima Daiichi Nuclear Power Plant in Japan. The incident brought back memories of the 1986 Chernobyl disaster and awoke many slumbering fears regarding nuclear safety. Many nuclear reactors were promptly shut down, and of the 40 operable nuclear reactors in Japan, only 9 were back online at the beginning of this year. Before the Fukushima Daiichi accident, $30 \%$ of Japan's electricity came from nuclear power. This percentage had dropped to $4 \%$ in 2017 (REF. $^{1}$ ).

To decommission, inspect for safety or restart these reactors, specialists are needed, and a side effect of the Fukushima Daiichi accident is that the nuclear industry has trouble attracting new talent ${ }^{2}$. Students' interest in jobs in the nuclear industry is declining and a serious shortage of skilled workers may be looming ${ }^{2}$. Adding to the mix, the financial troubles of Toshiba - one of the major nuclear power companies in Japan - does not paint a rosy picture for nuclear research and industry in Japan. But is this representative of the situation worldwide?

Currently about $11 \%$ of the world's electricity is generated by some 450 nuclear power reactors, and 60 more reactors are under construction ${ }^{1}$. Looking at the electricity produced by nuclear plants each year ${ }^{1}$, the dip following the Fukushima Daiichi accident seems relatively small. As Gail Marcus explains in a Comment in this issue, the situation of nuclear power worldwide is as

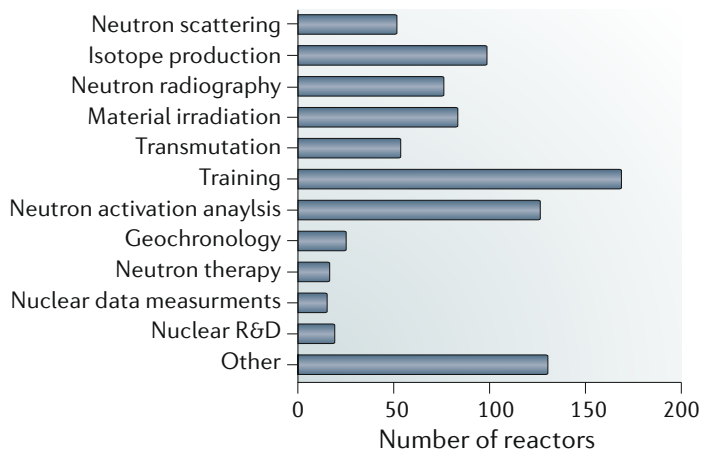

Fig. 1 | The diverse applications of research nuclear reactors. Data from $\mathrm{REF}^{3}$.

complicated as it has always been, but there are some positive developments in terms of public opinion and research and development. In a Comment, Paul Howarth is optimistic about the future of the nuclear industry, as he outlines the evolution of nuclear reactor technologies and discusses the challenges and opportunities in decommissioning and maintaining old reactors and deploying new ones.

The majority of the world's reactors are 40 or more years old. Among them are most of the research reactors, which are now being shut down, a process that has broad, including some unobvious, consequences. Research reactors have many uses, as shown in FIG. 1, from sources of medical radioisotopes and neutrons to facilities for education and training. The shortage of reactors used as training facilities is a problem in Japan $^{2}$ and worldwide. As John Carpenter explains in a Comment, losing the small research reactor neutron sources is problematic for education and training and for research. But new compact accelerator-driven neutron sources are being developed to fill this gap.

Many factors influenced the development of nuclear research and industry, and the Fukushima Daiichi accident and subsequent shut down of nuclear reactors is certainly one of them. But 8 years on, the current situation may not be as dire as one might assume. New reactors are under construction and there are new developments and opportunities for research. As Howarth points out, the future of nuclear industry relies on nurturing a skilled workforce and engaging with other industry sectors. We believe that students have no reason to hesitate before enrolling in nuclear engineering programmes and there are plenty of opportunities for researchers from varied backgrounds to get involved.

1. World Nuclear Association. Nuclear power in the world today. World Nuclear Association http://www.world-nuclear.org/ information-library/current-and-future-generation/nuclearpower-in-the-world-today.aspx (updated January 2019).

2. Kikuchi, D. Nuclear energy industry lacks new talent as Fukushima fallout turns of graduates. the japan times https://www.japantimes. co.jp/news/2017/03/10/national/nuclear-energy-industry-lacksnew-talent-fukushima-fallout-turns-off-graduates/\#.XGKRaDGnxhE (2017).

3. Research Reactor Database. Reactor search. International Atomic Energy Agency https://nucleus.iaea.org/RRDB/RR/ReactorSearch. aspx (February 2019). 